\title{
Presentación
}

\section{Geopolítica del transporte}

Alejandro Rascovan

Facultad de Ciencias Sociales y Grupo de Estudios sobre Fronteras y Regiones, Instituto de Geografía, Facultad de Filosofía y Letras, Universidad de Buenos Aires, Argentina. https://orcid.org/oooo-0002-5832-883X

\section{La geopolítica (crítica) cómo método para analizar los transportes y los territorios}

En el número 15 de esta revista, Kralich (2016) explicaba que a lo largo de los años se habían tratado diversas problemáticas teóricas y empíricas, en diferentes escalas geográficas y acerca de múltiples modos de transporte. Este dossier busca retomar ese espíritu.

Sin embargo, a diferencia de otros números donde el eje fue un modo de transporte específico (automóvil, bicicleta, etc.) o un país (Brasil, Argentina) o la región Metropolitana de Buenos Aires, las temáticas tratadas parecen, a primera vista, no tener una conexión directa. ¿Entonces, qué vincula a los satélites la empresa argentina Arsat con los grandes proyectos de infraestructura de la Ruta de la Seda llevada adelante por China con el Aeropuerto low cost de El Palomar en el conurbano bonaerense con el Tampão de Darién en la frontera brasileño-colombiana y la ruta Pan-Americana?

Los vínculos son dos. En primer lugar todos los temas son de gran actualidad y con importante preponderancia tanto en medios de comunicación como debates académicos como agenda política. Pero la pertinencia coyuntural no es la conexión a destacar entre estas cuatro temáticas. De acuerdo a Ladis K.D. Kristof, la geopolítica se concentra en los fenómenos políticos a partir de interpretaciones geográficas (Boniface, 2011). El vínculo entre los cuatro trabajos de este dossier es metodológico. Desde una perspectiva geopolítica se analizan las relaciones entre transportes y territorios.

El concepto de geopolítica podría encontrarse entre los más difundidos de las ciencias sociales. Además existen usos controvertidos y contrapuestos a lo largo de la historia que le otorgan un peso simbólico distintivo. Comenzando a principios del siglo XX y hasta la década de 1950, la geopolítica era utilizada principalmente por autores europeos como parte del entramado teórico que justificaba el expansionismo e imperialismo de las naciones. El territorio como soporte de una nación y ésta, a su vez, como reservorio de la raza. Estos usos y sus correlatos militaristas llevaron a que geopolítica deje de ser un término aceptable en las ciencias sociales tras el final de la segunda Guerra Mundial. Durante la década de 1970 la geopolítica como concepto y campo de estudio sufrió grandes cambios. Desde disciplinas sociales ya 
establecidas como la geografía y las relaciones Internacionales diversos autores con perspectivas teóricas disimiles revivieron a la geopolitica para explicar, sobre todo, la Guerra Fría (Dodds, 2014).

Por un lado, desde la academia norteamericana, el también Secretario de Estado Henry Kissinger escribió en 1979 The White House Years problematizando sobre el orden mundial en aquellos años. Kissinger, exponente de la corriente realista dentro de las relaciones internacionales abrió el campo para retomar cuestiones geopolíticas, asociando este concepto a conflicto internacional. En paralelo, surgió una corriente crítica a partir de los trabajos del francés Yves Lacoste y del norteamericano Peter Taylor. Esta geopolítica crítica se convirtió con el correr de los años en una de las principales líneas analíticas. Entre estas dos geopolíticas existe una diversidad temática y teórica lo suficientemente amplia como para cuestionarse si es correcto que ambas se llamen de la misma forma.

Nuestro dossier retoma de la escuela crítica una búsqueda por el análisis acerca de los intereses de los actores sociales y sus representaciones expresadas de manera territorial. En ese sentido, los cuatro artículos comparten una preocupación por el territorio. Estos cuatro artículos además tienen como característica trabajar con perspectivas multiescalares, es decir, no es únicamente a nivel local o global que se mueven los actores sociales e intereses analizados, sino que cada problemática dicta el alcance. Esta es una de las notas salientes de estos estudios geopolíticos. El juego de escalas propuesto en los artículos implica pensar configuraciones escalares en tanto órdenes regulatorios geográfico-institucionales y redes de actividades económicas entrelazadas. (Swyngedouw, 2004)

La perspectiva escalar nos acerca a la teoría del Sistema-mundo de Wallerstein. Para Swyngedouw (2010), fue Peter Taylor quien avanzó en mostrar cómo los procesos globales interactúan y son moldeados por las interacciones regionales y los sistemas localizados en una dinámica de desarrollo geográfico global. Las condiciones locales y regionales, los lugares y regiones se encuentran influidas y co-determinadas por dinámicas globales.

Otro de los puntos clave que surge de este dossier es el debate acerca del desarrollo. Sin dudas esta es una de las temáticas claves para la región, qué se entiende por desarrollo, cómo este es ideado, diagramado y llevado adelante por actores políticos, económicos, sociales, académicos. En esa dirección, la geopolítica nos aporta una perspectiva novedosa para analizar estas problemáticas. Los proyectos de desarrollo implican miradas opuestas y luchas de poder entre los actores sociales. En el caso de Arsat, por ejemplo, se nutre de divergencias acerca del uso de órbitas satelitales, la inversión pública y privada en tecnología de punta y el sector de las telecomunicaciones. Todas estas cuestiones centrales en los debates sobre el desarrollo nacional. En paralelo, el artículo sobre el aeropuerto de El Palomar también examina otro aspecto del desarrollo nacional argentino. El renovado uso de esta base de la Fuerza Aérea Argentina como aeropuerto de uso civil toca dos aspectos, por un lado las demandas de quienes viven en las cercanías y se ven perjudicados y, por el otro, la política aerocomercial de la gestión de Mauricio Macri, donde la aparición de empresas privadas low cost es la nota saliente, en un juego de tensiones constantes con la operación de la empresa estatal Aerolíneas Argentinas.

\section{Presentación de los artículos}

El artículo de Hurtado y Blinder parte de la geopolítica crítica y la perspectiva del Sistema-mundo para analizar la política de comunicación satelital en Argentina y las 
trayectorias de las empresas NahuelSat y ARSAT. El juego de escalas en este artículo propone entender a la Argentina como un país semiperiférico donde se entrelaza una trama de intereses acerca del desarrollo nacional. La construcción de los satélites geoestacionarios ARSAT 1 y 2 posicionan a la Argentina en un selecto club de naciones con capacidades industriales y tecnológicas, al mismo tiempo que resignifican las representaciones sobre la situación socio-económica del país y sus crisis. Los autores retoman el concepto de "ontología espacial" de Agnew y Corbridge en tanto evocan imágenes abstractas sobre diferenciales de poder y procesos sociales y económicos. En paralelo, retoman a Dittmer y su "orden geopolítico" en tanto relato sobre la estructura y la estabilidad del sistema. Este entramado de conceptos permite precisar las acciones políticas y las representaciones de un proyecto ambicioso como el plan espacial y satelital argentino, poniendo el juego los debates sobre desarrollo nacional, industria, ciencia y tecnología, transporte de información y el lugar del país en el mundo que viene.

Siguiendo las problemáticas del desarrollo pero con eje en la frontera entre Panamá y Colombia, el artículo de Pereira Carneiro, Reolon y Portela, toma como eje una de las zonas más problemáticas del continente. Los autores analizan cómo la creación de áreas protegidas en las fronteras funciona como "tapón" para solucionar conflictos entre Estados vecinos. El Tapón de Darién es un área selvática donde la ruta panamericana -el conjunto de rutas que atraviesa el continente desde el sur de Argentina hasta el norte de Estados Unidos y que representa al proyecto imperial norteamericano- se encuentra obstruida. Durante casi un siglo esta región fue dejada inconexa adrede, sin embargo, con la expansión del proyecto integracionista de la Iniciativa para la Integración de Infraestructura Regional Suramericana (IIRSA) y su posterior incorporación al Consejo Suramericano de Planificación (COSIPLAN) en el marco de la Unión de Naciones Sudamericanas (UNASUR), significó un cambio de perspectiva y de intereses económicos y sociales sobre esta región. El artículo analiza de forma precisa el conflicto geopolítico que supone la construcción de 108 kilómetros de ruta y las perspectivas para la finalización de esta infraestructura a partir de una mirada ambiental, social y diplomática.

El artículo de Vadell, Secches y Burger también trabaja sobre las infraestructuras de transporte. El eje es la política de la República Popular de China conocida como la "Ruta de la Seda" y la "Ruta Marítima del Siglo XXI". Estas dos iniciativas significan uno de los desafíos políticos más grandes de la actualidad, en tanto entrelaza perspectivas y políticas acerca de la globalización neoliberal, las interconexiones en infraestructura y el lugar del comercio, las políticas exteriores de grandes y pequeños Estados. La geopolítica les permite, entonces, analizar el rol de la República Popular de China (RPC) en relación a una perspectiva global sobre rutas de transporte, los cambios necesarios en las instituciones de la gobernanza global y las reacciones del Sur Global frente a estos procesos. A su vez, este trabajo nos obliga a situarnos en una posición de comprensión frente a las formas de la acción política en China. Los autores explican de forma clara la imposibilidad de pensar siguiendo la costumbre occidental de opuestos/ conflictivos en tanto dialéctica fundamental. Este punto es clave en la política exterior de nuestros países donde se ponen en juego cuestiones morales y económicas en la balanza. Pero a su vez, la política exterior de China no busca imponer recetas económicas y políticas a los países del Sur Global a cambio de inversiones, como es tradición norteamericana. La infraestructura de transporte se vuelve entonces piedra angular del proyecto geopolítico chino y abre un escenario de incertidumbre para occidente y para los países del Sur Global y sus necesidades de desarrollo. Una de las claves de los estudios geopolíticos que proponemos para este dossier implica la interdisciplinariedad. En este artículo, que podría leerse como puramente de política exterior, nos encontramos con aportes de K. Polanyi para entender la dicotomía dicotomía desacople o desincrustación (dis-embeddedness) e institucionalización del mercado (embeddedness) para la globalización del siglo XXI. 
Finalmente, el artículo de Soldano y Perret Marino nos retrotrae a la Argentina para hacer foco, desde una perspectiva geopolítica con eje en lo local, en las problemáticas del aeropuerto de El Palomar en la región metropolitana de Buenos Aires. Las autoras analizan los conflictos y las disputas en torno al aeropuerto desde una mirada histórica por fuera del dualismo conservación-modernización. La geopolítica local, en este caso, les permite a las autoras retomar una mirada cultural sobre el imaginario urbano y los conflictos entre los diversos actores. El aeropuerto, que fue durante décadas una base área de la Fuerza Aérea Argentina funciona como fragua -de identidad- del suburbio donde está emplazada. Sin embargo, hoy coexisten miradas contrapuestas entre ambientalistas, patrimonialistas (que proponen que el sitio debe ser protegido y conservado debido a los delitos de lesa humanidad y violación de los derechos humanos allí cometidos durante la última dictadura militar) con agrupaciones a favor y en contra del aeropuerto como Stop FlyBondi. La política aeronáutica denominada "revolución de los aviones" por el presidente Macri y el ministro de Transporte Dietrich tuvo como punto más fuerte la utilización de la base aérea de El Palomar como aeropuerto civil para empresas low cost. Entre estas se encuentran FlyBondi y JetSmart como principales operadoras del aeropuerto. La disputa geopolítica por El Palomar involucra lecturas socio-históricas con perspectivas sobre la política aerocomercial y asociaciones vecinales. Como explican las autoras, desde el comienzo, este territorio estuvo atravesado por idearios de progreso y es en esa clave que se debe entender el conflicto actual.

La potencialidad y riqueza que se encuentra en este dossier conjuga una pluralidad de temas y modos de transporte, de teorías y realidades que encuentran ejes en común a partir de las lecturas geopolíticas. Nos encontramos con una multiplicidad de variables en cada uno de los trabajos que obliga a salir de perspectivas simplistas y focalizadas. La geopolítica, como perspectiva metodológica lleva a análisis comprensivos sobre las acciones de los actores políticos. Este dossier abre la posibilidad de seguimiento de los mismos temas ya que estos conflictos van a seguir estando presentes en los años venideros. 


\section{Q Bibliografía}

» Boniface, P. (2011). Qu'est-ce que la géopolitique? (G. Eyrolles, Ed.). Paris: IRIS.

»Dodds, K. (2014). Geopolitics. A very short intrudicion. Oxford: Oxford University Press.

» Kralich, S. (2016). Celebrando tres décadas de trabajo en Geografía del Transporte (carta a los lectores). Revista Transporte y Territorio, 15, 2-15.

»Swyngedouw, E. (2004). Globalisation or "glocalisation"? Networks, territories and rescaling. Cambridge Review of International Affairs, 17(1), 25-48. https://doi. org/10.1080/0955757042000203632

»Swyngedouw, E. (2010). Place, Nature and the Question of Scale: Interrogating the Production of Nature. Diskussionpapier No. 5. Berlin. Disponible en: https:// edoc.bbaw.de/frontdoor/index/index/docld/859

\section{Alejandro Rascovan / alejandrorascovan@gmail.com}

Licenciado en Ciencia Política de la Universidad de Buenos Aires (UBA). Doctor en Ciencias Sociales por la UBA y en Socio-economía del Desarrollo (EHESS), fue becario doctoral y postdoctoral del IMHICIHU-CONICET. Actualmente se desempeña como docente en Teoría de las Relaciones Internacionales (FSOC-UBA) y es miembro del Grupo de Estudios sobre Fronteras y Regiones (GEFRE). 